\title{
The Influence of Weather Conditions on Rates of Return of Polish Equity Indices
}

\author{
Krzysztof Borowski ${ }^{1}$ \\ ${ }^{1}$ Warsaw School of Economics, Warsaw, Poland \\ Correspondence: Krzysztof Borowski, Warsaw School of Economics, al. Niepodleglosci 162, 02-519 Warsaw, \\ Poland. Tel: 485-1027-5217. E-mail: krzysztof.borowski@sgh.waw.pl
}

Received: January 7, 2016

Accepted: January 23, 2015

Online Published: March 25, 2016

doi:10.5539/ijef.v8n4p183

URL: http://dx.doi.org/10.5539/ijef.v8n4p183

\begin{abstract}
The influence of the weather on human behavior have been featured in many, not only scientific publications. This paper tests the hypothesis that the one-session average rates of return of equity indices (WIG, WIG20, mWIG40 and sWIG80) calculated for the different weather conditions differ in two populations. The atmospheric conditions taken into consideration in this paper are as follows: maximum and minimum daily temperature, sunny hours, rainfall, maximum and average wind velocity, atmospheric pressure, snow depth, sun energy ultraviolet radiation index. In the analyzed period, the impact on the daily rates of return was observed in the case of the following weather conditions: maximum daily temperature, sunny hours, rainfall, maximum wind velocity and atmospheric pressure. The other analyzed weather conditions such as average wind velocity, minimum daily temperature, snow depth, sun energy ultraviolet radiation index, turned out to be irrelevant. Thus, the influence of some weather condition on registered rates of return on the Polish equity markets has been proved.
\end{abstract}

Keywords: market efficiency, weather influence, market anomalies, behavioral finance

\section{Introduction}

\subsection{Introduction to the Problem - Weather Influence on Investors Decisions}

Seasonality of equity market has a long history although the academic research has been dominated by efficient market theory introduced by Fama (1970, 1991). Hirshleifer (2001), Hirshleifer and Shumway (2003) proved that psychologists documented correlation between sunshine and human behavior. Sunshine was lined to tipping (Rind, 1996) and lack of sunshine to depression (Eagles, 1994). According to Tietjen and Kripke (1994) the number of sunny hours influenced the number of committed suicides. People feel good when the sun shines and are more optimistic, consequently they are prone to open a long position in stocks what leads to the higher level of stock prices - therefore the weather influence on investors is very often discussed in papers dedicated to behavioral finance (Akhtari, 2011).

The main purpose of this paper is to verify the null hypothesis that the difference of one-session average rate of return calculated for the session, when the particular atmospheric conditions were present, and the one-session average rate of return, calculated for all sessions, when the particular atmospheric conditions were absent, is equal zero. The weather conditions analyzed in this research are as follows: maximum and minimum daily temperature, sunny hours, sun energy, rainfalls, maximum and average wind velocity, atmospheric pressure, snow depth and ultraviolet radiation. This is the first research regarding weather conditions influence on rates of return on the polish equity market.

\subsection{Literature Review}

The scientific literature dedicated to the weather influence on the capital market is not robust. According to Roll (1992) "weather data should be used in assessing the information processing ability of financial markets" and "weather is a genuinely exogenous economic factor". Saunders (1993) research was one of the first studies dedicated to the effects of cloud cover on stock returns. The author concentrated on daily returns of the Dow Jones Industrial Average in the time span of 1927-1989, applying the "percentage of cloud cover from sunrise to sunset" according to the New York weather station closest to Wall Street. Saunders (1993) found that stock returns are lower during the session of $100 \%$ cloud cover than on days when cloud cover was $20 \%$ or less and 
discovered that the weather effect impact on rates of return was higher in the period of 1982-1989 then in the previous analyzed period 1962-1982. To the similar conclusion came Akthari (2011) who based his research on the period of 1948-2010 in USA and noticed that the weather effect was stronger in some periods.

Hirshleifer and Shumway (2003) based on the data from 26 stock exchanges for the period of 1982-1997, proved that sunny weather was associated with an upbeat mood of investors and found the strong correlation between stock rates of return and sunshine. The authors discovered that stock returns tended to be higher on sunny days but other weather conditions such as rain and snow were unrelated to returns.

Taking into consideration seasonal time-variation of risk premia in stock returns, Kamstra et al. (2001), referring to yearly daylight fluctuations, introduced the Seasonal Affective Disorder (SAD) and found statistical significance relationship between stock returns and SAD. According to the authors, the lack of sunlight induced investors depression, what increased their risk aversion and affected stock valuation. Keef and Roush (2007) based on 26 international stock exchanges showed the relation between the sunshine effect, per capita GDP and latitude. They found no effect in the stock exchanges situated near the equator and a big influence on northern exchanges.

Trombley (1997) suggested that the relation between weather conditions and stock return is not as obvious as Saunders (1993) claimed, and proved that the weather influence on rates of return appeared in only one of the three periods examined, and the effect was limited to only a few months of the year, while ceasing in the others. According to Trombley (1997) the strongest weather effect impact on US stock prices, was observed in the period of 1990-1997. Loughran and Schulz (2004) found the little evidence conforming that cloudy weather in the city in which analyzed company was based, affected its returns.

Pardo and Valor (2002) investigated the relation between weather and rates of return on the Spanish market (Madrid Stock Exchange) and analysing daily closing prices, they proved that in the examined period there was no impact of sunny hours and humidity levels on equity rates of return. Another negative evidence was presented by Kramer and Runde (1997), who whilst investigating weather effect on Frankfurt Stock Exchange in the period of 1960-1990, discovered that weather conditions were irrelevant to the short-term stock returns. According to them the positive or negative results relating weather influence on market returns result from different statistical methods applied by researchers.

\section{Method}

According to the adopted methodology, the survey covers two populations of returns, characterized by normal distributions. On the basis of two independent populations of rate of returns, which sizes are equal $n_{1}$ and $n_{2}$ respectively, the hypotheses $H_{0}$ and $H_{l}$ should be tested with the use of statistics $z$ (Osinska 2006, pp. 43-44):

$$
\mathrm{z}=\frac{\overline{\mathrm{r}_{1}}-\overline{\mathrm{r}_{2}}}{\sqrt{\left(\frac{\mathrm{s}_{1}^{2}}{\mathrm{n}_{1}}+\frac{s_{2}^{2}}{\mathrm{n}_{2}}\right)}}
$$

where:

$\overline{r_{1}}$-average rate of return in the first population,

$\overline{r_{2}}$-average rate of return in the second population,

$n_{1}$ - number of rates of return in the first population,

$n_{2}$ - number of rates of return in the second population,

$S_{1}^{2}$ - variance of rates of returns in the first population,

$S_{2}^{2}$ - variance of rates of returns in the second population.

The Formula 1 can be used in the case of normally distributed populations, when the populations variances are unknown but assumed equal. The number of degrees of freedom is equal to: $d f(1)=n_{1}+n_{2}-2$.

Because the population variances are unknown, it might occur that the populations variances are unequal. In such case we can use the Formula 1 to calculate the $z$ statistics, but the number of degrees should be modified according to the following formula (Defusco et al., 2001, p. 335):

$$
d f(2)=\frac{\left(\frac{s_{1}^{2}}{n_{1}}+\frac{s_{2}^{2}}{n_{2}}\right)^{2}}{\frac{\left(s_{1}^{2} / n_{1}\right)^{2}}{n_{1}}+\frac{\left(s_{2}^{2} / n_{2}\right)^{2}}{n_{2}}}
$$


In case of two populations, both with equal or unequal variances, the null hypothesis $H_{0}$ and alternative hypothesis $H_{l}$ regarding equality of rates of return in two populations, can be formulated as follows:

$$
\begin{gathered}
H_{0}: E\left(r_{1}\right)=E\left(r_{2}\right) \\
H_{1}: E\left(r_{1}\right) \neq E\left(r_{2}\right)
\end{gathered}
$$

In particular: for the analysis of the daily rates of return, if $\overline{r_{1}}$ is the daily average rate of return calculated for sessions when the particular weather condition was observed (the first population), then $\overline{r_{2}}$ is the daily average rate of return computed for all other session, when the particular weather condition was not observed (the second population).

In all analyzed cases, the p-values will be calculated with the assumption that the populations variances are unknown, but:

a) population variances are assumed equal - p-value(1),

b) population variances are assumed unequal - $\mathrm{p}$-value(2).

If the p-value is less than or equal to 0,05 ; then the hypothesis $H_{0}$ is rejected in favor of the hypothesis $H_{l}$. Otherwise, there is no reason to reject hypothesis $H_{0}$.

As the last part of the calculation will be carried out F-test using the F-statistics (so called Fisher-Snadecor statistics) for equality of variances of two population rates of return, where $F=\frac{s_{i}^{2}}{s_{j}^{2}}$, with the condition that: $S_{i}^{2}>S_{j}^{2}$ and that $i, j=1,2$; and the degrees of freedom are equal:

$n_{i}$ - for variance in the numerator of $F$,

$n_{j}$ - for variance in the denominator of $F$.

If F-test (computed for $\alpha=0,05$ ) is lower than F-statistics, there is no reason to reject the null hypothesis, which can be formulated as follows:

$$
{ }_{0}^{F} H: S_{1}^{2}=S_{2}^{2}
$$

The alternative hypothesis may be defined by the ensuing equation:

$$
{ }_{1}^{F} H: S_{1}^{2} \neq S_{2}^{2}
$$

In the case, when there is no reason to reject the null hypothesis concerning equality of variances of two observed returns, the p-value(1) should be compared with the critical value 0,05 ; otherwise the p-value(2) will be used - that explains the reason of applying p-value in the following part of the paper.

The research is divided into ten parts, in each of them, the following weather condition will be analyzed:

a) Minimum daily temperature (in degrees Centigrade) - divided into 13 categories: [below -15, (-15,-10), (-10, $-5),(-5,0),(0,5),(5,10),(10,15),(15,20),(20,25),(25,30),(30,35),(35,40)$ and above 40

b) Maximum daily temperature (in degrees Centigrade) - divided into 13 categories: [below $-15,(-15,-10)$, $(-10,-5),(-5,0),(0,5),(5,10),(10,15),(15,20),(20,25),(25,30),(30,35),(35,40)$ and above 40]

c) Number of sunny hours (in hours) - divided into 13 categories: (less than 1, 1-2, 2-3, 3-4, 4-5, 5-6, 6-7, 7-8, 8-9, 9-10, 10-11, 11-12 and higher than 12).

d) Daily rainfall (in millimeters) - divided into 13 categories: (0, 0-5, 5-10, 10-15, 15-20, 20-25, 25-30, 30-35, 35-40, 40-45, 45-50, 50-55 and higher than 55

e) Average wind velocity (in $\mathrm{km} / \mathrm{h}$ ) - divided into 13 categories (less than $1,1-5,5 ; 5,5-11 ; 11-19 ; 19-28 ; 28-38$; $38-49 ; 49-61 ; 61-74 ; 74-88 ; 88-102 ; 102-117$ and above 117 )

f) Maximum wind velocity (in $\mathrm{km} / \mathrm{h}$ ) - divided into 13 categories (less than $1,1-5,5 ; 5,5-11 ; 11-19 ; 19-28$; $28-38$; 38-49; 49-61; 61-74; 74-88; 88-102; 102-117 and above 117)

g) Snow depth (in millimeters) - divided into 13 categories (below 2, 2-4, 4-6, 6-8, 8-10, 10-12, 12-14, 14-16, $16-18,18-20,20-22,22-24$ and above 24)

h) Average atmospheric pressure (in hectopascals) - divided into 13 categories (below 990, 990-994, 994-998, 998-1002, 1002-1006, 1006-1010, 1010-1014, 1014-1018, 1018-1022, 1022-1026, 1026-1030, 1030-1034 and higher than 1034).

i) Sun energy (in Watts per square meter) - divided into 13 categories (less than 100, 100-200, 200-300, 
$300-400,400-500,500-600,600-700,700-800,800-900,900-1000,1000-1100,1100-1200$ and higher than 1200).

j) Index of ultraviolet radiation - divided into 5 categories (below 2, 2-5, 5-7, 7-10 and above 10).

All analyzed weather conditions refer to Warsaw and were measured in the period of 01.01.2008 - 30.06.2015. Some of the weather conditions data was downloaded from the website: http://www.andretti.pl on which are revealed details regarding ultraviolet radiation index. The statistical hypothesis were tested for the following indices: WIG (the broad market index), WIG20 (blue chips index), mWIG40 (medium capitalization companies index) and sWIG80 (small capitalization companies index).

\section{Results}

\subsection{Analysis of the Maximum Daily Temperature Influence on Rates of Return}

The results of testing the null hypothesis permit to draw the following conclusions:

1) The null hypothesis regarding equality of variances of daily average rates of return in two populations, was rejected (for $\alpha=5 \%$ ) in the following cases:

a) WIG index - categories $[(-10,-5),(10,15)$ and $(15,20)]$.

b) WIG20 index - categories $[(-10,-5)$ and $(20,25)]$.

c) mWIG40 index - categories: $[(-10,-5),(-5,0),(0,5),(10,15)$ and $(15,20)]$.

d) sWIG80 index - categories: $[(-10,-5),(-5,0),(0,5),(10-15)$ and $(15,20)]$.

2) The null hypothesis regarding equality of two average rates of return in two populations was rejected in the following cases ( $\mathrm{p}$-value shown in parenthesis):

a) WIG index - category 10-15 $(0,0176)$.

b) WIG20 index - category 10-15 (0,0278).

c) sWIG80 index - categories $(-15,-10)$ and $(10,15)$ for which the p-value were equal $(0,0040)$ and $(0,0093)$, respectively. For category $(-10,-5)$ the $\mathrm{p}$-value was equal to 0,0564 .

\subsection{Analysis of the Minimum Daily Temperature Influence on Rates of Return}

The null hypothesis regarding equality of variances of daily average rates of return in two populations, was rejected (for $\alpha=5 \%$ ) in the following cases:

a) WIG index - categories [below -15, (-15, -10), (-5,0), (0,5), (5-10) and (25-30)].

b) WIG20 index - categories [below -15, (-15, -10), (5-10) and (25-30)].

c) mWIG40 index - categories [ $(-15,-10),(-10,-5),(-5,0),(0,5),(5,10),(10,15)$ and $(15,20)]$.

d) sWIG80 index - categories [ $(-15,-10),(-10,-5),(-5,0),(0,5),(5,10),(10,15),(15,20)$ and $(20,25)]$.

In all analyzed cases, the p-value was higher than 0,05 ; and therefore there was no reason to reject the null hypothesis regarding equality of averages in two group of populations.

\subsection{Analysis of the Number of Sunny Hours Influence on Rates of Return}

The results of testing the null hypothesis permit to draw the following conclusions:

1) The null hypothesis regarding equality of variances of daily average rates of return in two populations, was rejected (for $\alpha=5 \%$ ) in the following cases:

a) WIG index - categories (below 1, 1-2, 6-7, 7-8 and 10-11).

b) WIG20 index - categories (below 1, 1-2, 2-3 and 7-8).

c) mWIG40 index - categories (below 1, 1-2, 4-5, 5-6, 6-7 and 7-8).

d) sWIG80 index - categories: (1-2, 4-5, 5-6, 7-8 and 10-12).

2) The null hypothesis regarding equality of two average rates of return in two populations was rejected in the following cases ( $\mathrm{p}$-value shown in parenthesis):

a) WIG index - category 5-6 (0,0335). For the category 9-10, the p-value was equal 0,0678.

b) mWIG40 - category 5-6 (0,0262).

c) sWIG80 - category 9-10 (0,0224). For categories 5-6 the p-value was equal to 0,0547. 
d) WIG20 index. For categories 4-5 and 5-6 the p-value were equal to 0,0535 and 0,0551, respectively.

The one session average rates of return for each of the analyzed indices broken down into the daily number of sunny hours are presented on the figure 1. The highest number of daily average rates of return highest than zero was observed in the case of mWIG40 (9) and the lowest for WIG20 (6), whilst for two other indices this number mounted to 8 .

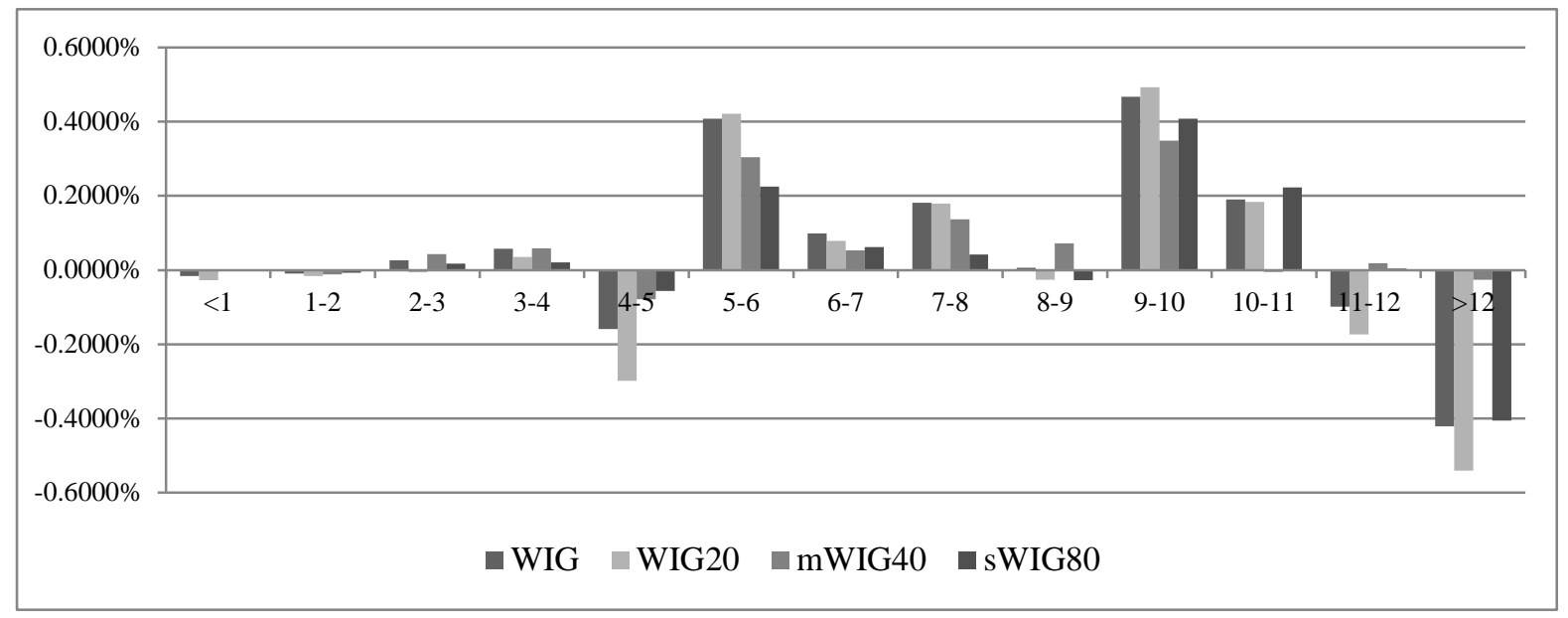

Figure 1 . The one session average rates of return for 4 analyzed indices broken down into the daily number of sunny hours

Source: own calculations.

\subsection{Analysis of the Daily Rainfall Influence on Rates of Return}

The results of testing the null hypothesis permit to draw the following conclusions:

1) The null hypothesis regarding equality of variances of daily average rates of return in two populations, was rejected (for $\alpha=5 \%$ ) in the following cases:

a) WIG index - category 6-10.

b) WIG20 - categories: 0-5 and 6-10.

c) mWIG40 - category: 6-10.

d) sWIG80 - categories: 6-10 and 30-35.

2) The null hypothesis regarding equality of two average rates of return in two populations was rejected in the following cases (p-value shown in parenthesis):

a) WIG - category 20-25 (0,0197).

b) WIG20 - categories: 20-25 (0,0430), 40-45 (0,0241). For the category 35-40 the p-value was equal to 0,0885 .

c) mWIG40 - category: 20-25 (0,0181).

The one session average rates of return for each of the analyzed indices broken down into the daily amount of rainfall are presented on the figure 2 . The highest number of daily average rates of return highest than zero was observed in the case of mWIG40 (8) whilst for three remaining indices it was equal to 7. 


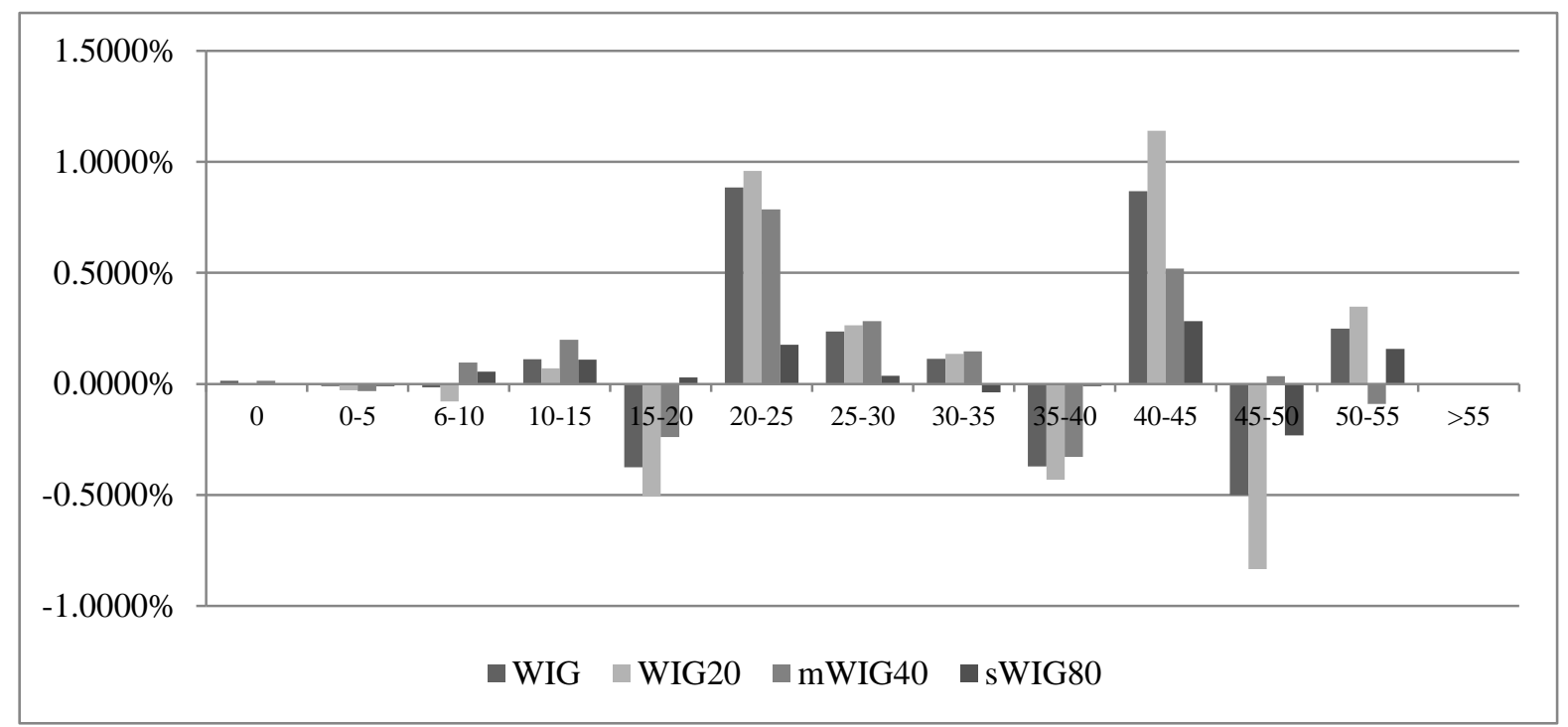

Figure 2. The one session average rates of return for 4 analyzed indices broken down into daily amount of rainfall

Source: own calculations.

\subsection{Analysis of the Average Wind Velocity Influence on Rates of Return}

The null hypothesis regarding equality of variances of daily average rates of return in two populations, was rejected (for $\alpha=5 \%$ ) in the following cases:

a) WIG index - categories: less than 1 and 1-5,5.

b) WIG20 index - categories: less than 1 and 1-5,5.

c) mWIG40 index - categories: less than 1 and 11-19.

d) sWIG80 index - categories: less than 1 and 11-19.

In all analyzed cases, the p-value was higher than 0,05 ; and therefore there was no reason to reject the null hypothesis regarding equality of averages in two group of populations.

\subsection{Analysis of the Maximum Wind Velocity Influence on Rates of Return}

The results of testing the null hypothesis permit to draw the following conclusions:

1) The null hypothesis regarding equality of variances of daily average rates of return in two populations, was rejected (for $\alpha=5 \%$ ) in the following cases:

a) WIG index - categories less than 1; 1-5,5; and 5,5-11.

b) WIG20 index - categories less than 1; 1-5,5; and 5,5-11.

c) mWIG40 - categories: 1-5,5; 5,5-11; 38-34 and higher than 117

d) sWIG80 - categories: less than 1; 1-5,5; 5,5-11 and 38-39.

2) The null hypothesis regarding equality of two average rates of return in two populations was rejected in the case of mWIG40 in category: 1-5,5, for which the p-value was equal to 0,0277. For the categories 5,5-11 and 28-28 the p-value were equal to 0,0529 and 0,0890, respectively.

\subsection{Analysis of the Snow Depth Influence on Rates of Return}

The null hypothesis regarding equality of variances of daily average rates of return in two populations, was rejected (for $\alpha=5 \%$ ) for all of analyzed indices in 13 categories.

In all analyzed cases, the p-value was higher than 0,05 ; and therefore there was no reason to reject the null hypothesis regarding equality of averages in two group of populations.

\subsection{Analysis of the Average Atmospheric Pressure on Rates of Return}

The results of testing the null hypothesis permit to draw the following conclusions: 
1) The null hypothesis regarding equality of variances of daily average rates of return in two populations, was rejected (for $\alpha=5 \%$ ) in the following cases:

a) WIG index - categories: 994-998, 1006-1010, 1010-1014, 1014-1018 and above 1030.

b) WIG20 index - categories: 994-998, 1010-1014, 1014-1018 and above 1030.

c) mWIG40 index - categories: less than 990, 1006-1010, 1030-1034 and above 1034.

d) sWIG80 index - categories: less than 990, 990-994, 998-1002, 10230-1034 and higher than 1034.

2) The null hypothesis regarding equality of two average rates of return in two populations was rejected in case of sWIG80 index in two categories (p-value shown in parenthesis): less than $990(0,0319)$ and 990-994 $(0,0355)$. For the category higher than 1034 the $\mathrm{p}$-value was equal to 0,0554 .

\subsection{Analysis of the Sun Energy on Rates of Return}

The null hypothesis regarding equality of variances of daily average rates of return in two populations, was rejected (for $\alpha=5 \%$ ) in the following cases:

a) WIG index - categories: less than 100, 300-400, 400-500, 500-600, 700-800 and 900-1000.

b) WIG20 index - categories: less than 100, 300-400, 400-500, 500-600, 700-800 and 900-1000.

c) mWIG40 index - categories: less than 100, 100-200, 500-600, 700-800, 900-1000 and more than 1200 .

d) sWIG80 index - categories: less than 100, 100-200, 200-300, 500-600, 700-800, 800-900, 1100-1200 and higher than 1200.

In all analyzed cases, the p-value was higher than 0,05 ; and therefore there was no reason to reject the null hypothesis regarding equality of averages in two group of populations.

\subsection{Analysis of Ultraviolet Radiation on Rates of Return}

The null hypothesis regarding equality of variances of daily average rates of return in two populations, was rejected (for $\alpha=5 \%$ ) in all categories except the last (e.g. higher than 10) for al analyzed indices.

In all analyzed cases, the p-value was higher than 0,05 ; and therefore there was no reason to reject the null hypothesis regarding equality of averages in two group of populations.

\section{Discussion}

The summary of obtained results is presented in the Table 1 . In the analyzed period, the impact on the daily rates of return was observed in the case of the following weather conditions: maximum daily temperature, sunny hours, rainfall, maximum wind velocity and atmospheric pressure. The other analyzed weather conditions such as average wind velocity, minimum daily temperature, snow depth, sun energy ultraviolet radiation index, turned out to be irrelevant. The influence on the one session rates of return was statistically important in the case of the maximum daily pressure higher than 10 and lower than 15 degrees Centigrade - this observations applies to indices: WIG, WIG20 and sWIG80. In the case of sWIG80 also differences between one session rates of return calculated for session when maximum temperature was higher than minus 15 and lower than minus 10 degrees Centigrade and average rate of return during all remaining sessions, turned out to be statistically important. Taking into consideration sunny hours from 5 to 6 , for indices WIG and mWIG40 and also from 9 to 10 in the case of sWIG80, we may conclude that the daily average rates of return calculated for these sessions was statistically different from the one session average rate of return for session, when the number of sunny hour was different. Analyzing the data regarding rainfall in the Table 1, it is easy to observe than then rainfall higher than 20 and lower than 25 millimeter had impact on the registered one session rates of return, in the case of the following indices: WIG, WIG20 and mWIG40. The rainfall higher than 40 and lower than 45 millimeter influenced also investors operating in the segment of blue chips (WIG20) but maximum wind velocity higher than 1 and lower than $5,5 \mathrm{~km} / \mathrm{h}$ affected investors dealing with medium capitalization companies (mWIG40). Regarding the influence of atmospheric pressure on investors, it was evident in the case of the small capitalization companies (sWIG80) and only when the pressure was very low (less than 990 and 990-994 hectopascals).

The result regarding the influence of sunny hours on the daily rates or return, confirm previous outcomes obtained by the Hirshleifer and Shumway (2003) and thereby deny the findings presented in the works of Pardo and Valor (2002) and Kramer and Runde (1997).

The main limitation of this research is the assumption of normal distribution of return rates of analyzed indices along with the use of price data gained from data source (website bossa.pl) as well as the unequal intervals of 
observations for different equity indices. Another strong constraint, affecting the obtained results, is the assumption that the weather condition in other parts of Poland are the same like in Warsaw. In making the interpretation of results, one should also remember that on the Warsaw Stock Exchange operate investors from other countries, where weather conditions can differ greatly from those in Warsaw.

The outcome may be regarded as a part of the ongoing discussions on the hypothesis of financial markets efficiency, which was introduced by Fama (1970).

Table 1 . The summary of obtained results - cases for which the null hypothesis regarding equity of average rates of return in two populations was rejected

\begin{tabular}{|c|c|c|c|c|}
\hline & WIG & WIG20 & mWIG40 & sWIG80 \\
\hline \multirow[t]{2}{*}{ Maximum daily temperature $\left({ }^{\circ} \mathrm{C}\right)$} & $10-15$ & $10-15$ & - & $(-15,-10)$ \\
\hline & & & & $10-15$ \\
\hline Sunny hours (hours) & $5-6$ & - & $5-6$ & $9-10$ \\
\hline \multirow[t]{2}{*}{ Rainfall (millimeters) } & $20-25$ & $20-25$ & $20-25$ & - \\
\hline & & $40-45$ & & \\
\hline Maximum wind velocity $(\mathrm{km} / \mathrm{h})$ & - & - & $1-5,5$ & - \\
\hline \multirow[t]{2}{*}{ Atmospheric pressure (hectopascals) } & - & - & - & Less than 990 \\
\hline & & & & 990-994 \\
\hline Average wind velocity $(\mathrm{km} / \mathrm{h})$ & - & - & - & - \\
\hline Minimum daily temperature $\left({ }^{\circ} \mathrm{C}\right)$ & - & - & - & - \\
\hline Snow depth (millimeters) & - & - & - & \\
\hline Sun energy $\left(w / \mathrm{m}^{2}\right)$ & - & - & - & - \\
\hline Ultraviolet radiation index & - & - & - & - \\
\hline
\end{tabular}

Source: own calculations.

\section{References}

Akthari, R. (2011). Reassessment of weather effect: Stock prices and Wall Street weather. Undergraduate Economic Review, 7, 1-25.

Defusco, R., McLeavey, D., Pinto, J., \& Runkle, D. (2001). Quantitative methods for investment analysis. Baltimore: United Book Press.

Eagles, J. (1994). The relationship between mood and daily hours or sunlight in rapid cycling bipolar illness. Biological Psychiatry, 36, 422-424. http://dx.doi.org/10.1016/0006-3223(94)91216-5

Fama, E. (1970). Efficient capital markets: A review of theory and empirical work. Journal of Finance, 25, 383-417. http://dx.doi.org/10.2307/2325486

Fama, E. (1991). Efficient capital markets II. Journal of Finance, 46, 1575-1617. http://dx.doi.org/10.1111/j.1540-6261.1991.tb04636.x

Hirshleifer, D. (2001). Investor psychology and asset pricing. Journal of Finance, 56, 1533-1597. http://dx.doi.org/10.1111/0022-1082.00379

Hirshleifer, D., \& Shumway, T. (2003). Good day sunshine: Stock markets returns and the weather. Journal of Finance, 58, 1009-1032. http://dx.doi.org/10.1111/1540-6261.00556

Kamstra, M., Kramer, L., \& Levi, M. (2001). Winter blues: Seasonal Affective Disorder (SAD) and stock market returns. Working paper, University of British Columbia.

Keef, S., \& Roush, M. (2007). A metaanalysis of the international evidence of cloud cover on stock returns. Review of Accounting and Finance, 6, 324-338.

Kramer, W., \& Runde, R. (1997). Stock and the weather: And exercise in data mining or yet another capita market anomaly. Empirical Economics, 22, 637-641.

Loughran, T., \& Schulz, P. (2004). Weather, stock returns and the impact of localized trading behavior. Journal of Financial and Quantitative Analysis, 39, 343-364. http://dx.doi.org/10.1017/S0022109000003100

Osinska, M. (2006). Ekonometria finansowa. Warszawa: PWE.

Pardo, A., \& Valor, E. (2002) Spanish Stock Returns: Where is the Weather Effect? European Financial 
Management, 9, 117-126. http://dx.doi.org/10.1111/1468-036X.00210

Rind, B. (1996). Effects on beliefs about weather conditions on tipping. Journal of Applied Social Psychology, 26, 137-147. http://dx.doi.org/10.1111/j.1559-1816.1996.tb01842.x

Roll, R. (1992). Weather. In P. Newman, M. Milgate, \& J. Eatwell (Eds.), The new Palgrave dictionary of money and finance. London: Macmillan Press.

Saunders, E. (1993). Stock prices and Wall Street weather. American Economic Review, 83, 1337-1345.

Tietjen, G., \& Kripke, D. (1994). Suicides in California (1968-1977) - Absence of seasonality in Los Angeles and Sacramento counties. Psychiatric $\quad$ Research, $161-172$. http://dx.doi.org/10.1016/0165-1781(94)90107-4

Trombley, M. (1997). Stock prices and Wall Street weather; Additional evidence. Quarterly Journal for Business and Economics, 36, 11-21.

\section{Copyrights}

Copyright for this article is retained by the author(s), with first publication rights granted to the journal.

This is an open-access article distributed under the terms and conditions of the Creative Commons Attribution license (http://creativecommons.org/licenses/by/3.0/). 